NBER WORKING PAPER SERIES

\title{
INTERNATIONAL WELFARE AND EMPLOYMENT LINKAGES ARISING FROM MINIMUM WAGES
}

\author{
Hartmut Egger \\ Peter Egger \\ James R. Markusen \\ Working Paper 15196 \\ http://www.nber.org/papers/w15196
}

\author{
NATIONAL BUREAU OF ECONOMIC RESEARCH \\ 1050 Massachusetts Avenue \\ Cambridge, MA 02138 \\ July 2009
}

The views expressed herein are those of the author(s) and do not necessarily reflect the views of the National Bureau of Economic Research.

NBER working papers are circulated for discussion and comment purposes. They have not been peerreviewed or been subject to the review by the NBER Board of Directors that accompanies official NBER publications.

(C) 2009 by Hartmut Egger, Peter Egger, and James R. Markusen. All rights reserved. Short sections of text, not to exceed two paragraphs, may be quoted without explicit permission provided that full credit, including $\odot$ notice, is given to the source. 
International Welfare and Employment Linkages Arising from Minimum Wages

Hartmut Egger, Peter Egger, and James R. Markusen

NBER Working Paper No. 15196

July 2009

JEL No. F12,F15,F16,F23,J30

\begin{abstract}
We formulate a two-country model with monopolistic competition and heterogeneous firms to reconsider labor market linkages in open economies. Labor-market imperfections arise by virtue of country-specific real minimum wages. Two principal experiments are considered. First, we show that trade liberalization under minimum wages differs significantly from trade liberalization under standard assumptions. In the former case, there is effectively a perfectly elastic supply of labor to production whereas in the conventional case it is assumed that aggregate labor supply is perfectly inelastic. Standard effects on marginal and average firm productivity are reversed in our model, yet there are significant gains from trade arising from employment expansion, an effect quite different from the source of gains from trade in the conventional approach. Second, we show that with firm heterogeneity an increase in one country's minimum wage triggers firm exit in both countries and thus harms workers at home and abroad. In an extension to our baseline model, we illustrate that offshoring production from the high-wage to the low-wage country within multinational firms lowers the scope for exporting the costs of a higher minimum wage to the trading partner.
\end{abstract}

\author{
Hartmut Egger \\ University of Bayreuth \\ hartmut.egger@uni-bayreuth.de \\ Peter Egger \\ ETH Zurich \\ egger@kof.ethz.ch
}

\author{
James R. Markusen \\ Department of Economics \\ University of Colorado \\ Boulder, CO 80309-0256 \\ and NBER \\ james.markusen@colorado.edu
}




\section{Introduction}

In an open economy, the consequences of labor market institutions are not confined to domestic workers but also spill over to foreign ones. This suggests a correlation in labor market outcome across countries due to institutional factors quite distinct from the dynamic transmission of shocks studied by macroeconomists. Figure 1 illustrates the respective correlation in unemployment rates of two major economic blocs, the European Union (EU; with 15 member countries as of 1995) and the United States for the time span 1984-2004. Two features of the relationship in the figure are notable. First, while the unemployment rate of the US is considerably lower than the respective rate in the $\mathrm{EU}$, unemployment is clearly an issue on both sides of the Atlantic (see Nickell, 1997; Scheve and Slaughter, 2001). Second, the relationship between the two unemployment rates is positive. ${ }^{1}$ Clearly, the unconditional correlation of unemployment rates does not reflect a causal relationship. However, there is evidence that labor market outcome in general and unemployment rates in specific are positively correlated across regions of various levels of aggregation (see Südekum, 2005; Patacchini and Zenou, 2007).

Academic interest in the consequences of labor market institutions in open economies has been sparked by the seminal work of Brecher (1974). Yet, an intuition for the positive relationship of unemployment rates in Figure 1 is not available from that or subsequent work. Developing a model to fill this gap is the aim of our paper. For this purpose, we deviate from two standard assumptions in the existing literature on international labor market linkages. On the one hand, we assume that labor market imperfections are not confined to one industrialized country or a subset of such countries but they are ubiquitous among industrialized economies. Clearly, institutions and, hence, the degree of labor market imperfections may differ across countries and so may the rates of involuntary unemployment. On the other hand, we consider heterogeneous firms that supply differentiated products. While it is uncontroversial that models of heterogeneous firms can improve our understanding about international trade patterns,

\footnotetext{
${ }^{1}$ Notice that the relationship would be similar when including observations prior to 1984 and after 2004 . However, we do not display a longer time series since the definition of European unemployment rates has changed between 1983 and 1984. Also, we do not consider more recent data since EU unemployment rates may have changed structurally in the aftermath of EU's Eastern Enlargement in 2004. Beyond that it is possible to assess the correlation in unemployment rates by considering dyadic correlations over a certain time span and comparing the number of positive and negative correlation coefficients. For instance one can do so for the following 25 OECD countries (all OECD members except of Czech Republic, Hungary, Poland, Slovak Republic, and Turkey) between 1992 and 2004. This is the country sample and time span for which unemployment rates have full coverage in the World Bank's World Development Indicators 2007. The lower triangular of the symmetric matrix of correlation coefficients has 300 entries. Of those, 94 are negative while 206 are positive. Hence, the issue we address is relevant not only at the level of country blocs but also across dyads.
} 


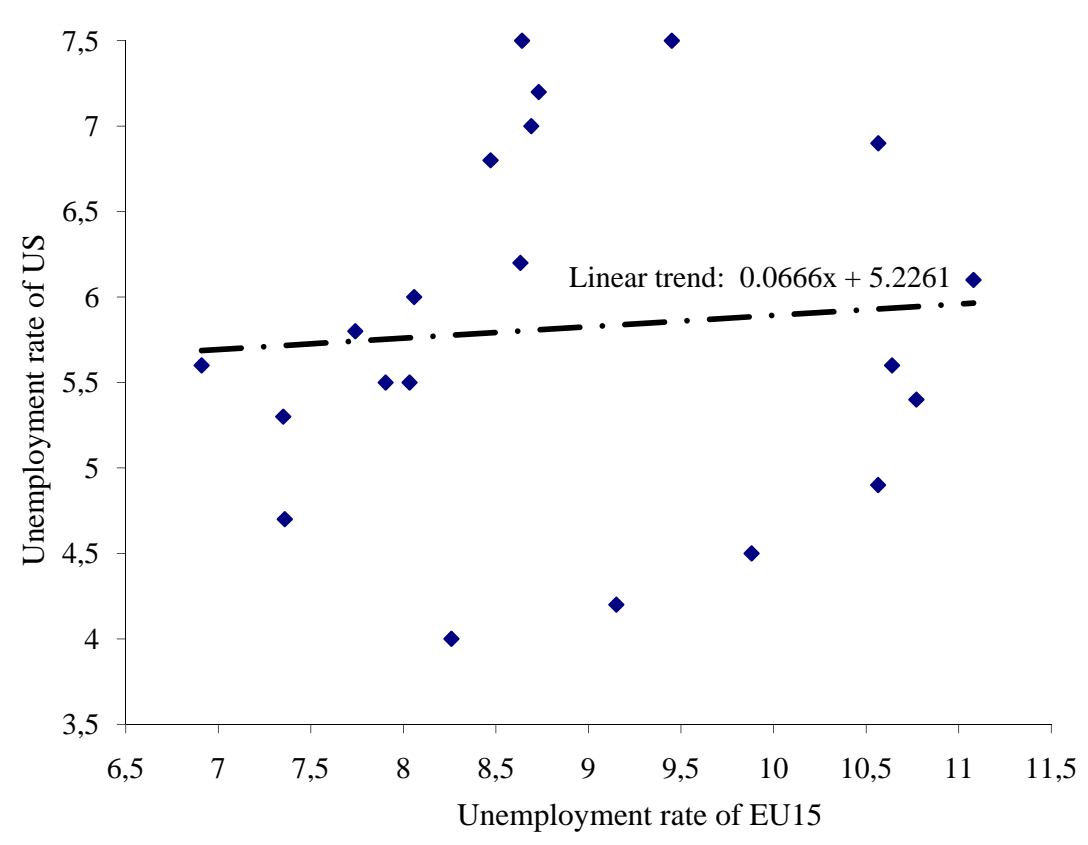

Source: World Bank, World Development Indicators 2007

Figure 1: Unemployment rates of the US and the EU15 (1984-2004)

there is only a handful of studies that addresses the interaction of firm heterogeneity and labor market imperfections in the process of globalization, none of them focussing on international spillover effects in the case of asymmetric institutional settings. ${ }^{2}$ As we show in this paper, firm heterogeneity is elemental for a positive correlation of unemployment rates across countries in response to a change in labor market tightness in just one economy. The reason for the latter is that the composition of producers changes which counteracts the cross-border spillover effects of imperfect labor markets in models with homogeneous firms.

To substantiate the role of firm heterogeneity for international labor market linkages, it is worth looking at the pioneering work of Davis (1998) who was the first one to address crossborder spillovers between European and US labor markets. Relying on a $2 \times 2$ HeckscherOhlin-type model with minimum wages in Europe and a perfect labor market in the US, Davis concluded that European unemployment props up US wages. This result is immediately intuitive with international factor price equalization (i.e., with diversification of production and in the absence of trade impediments), and it remarkably qualifies the widely accepted view that rising

\footnotetext{
${ }^{2}$ Recent contributions that look at the interaction of firm heterogeneity and labor market institutions in the process of globalization include Davis and Harrigan (2007); Davidson, Matusz, and Shevchenko (2008); Helpman, Itskhoki, and Redding (2008); Egger and Kreickemeier (2009).
} 
European unemployment and rising US wage inequality are "two sides of the same coin" (Krugman, 1994, p. 31). As pointed out by Davis (1998), the latter conclusion would only be valid if Europe and the US were isolated from each other but not if they are linked through international trade flows. With factor price equalization due to trade linkages, a binding European minimum wage raises unskilled wages in the US and thus reduces wage inequality there. ${ }^{3}$ As noted by Davis, this finding is robust to considering homogeneous, imperfectly competitive firms under monopolistic competition (rather than perfectly competitive ones) and, hence, the assumption of perfect competition in a traditional trade model is not responsible for this outcome. Rather, it will be illustrated below that firm homogeneity and, hence, the exclusion of adjustments in the composition of producers is crucial for positive cross-border spillovers of national labor market tightness.

To conduct our analysis, we set up a model in which firms produce and supply differentiated intermediate goods under monopolistic competition as in Ethier (1982) and Markusen (1989). Intermediate goods production uses labor as the only input and intermediates are aggregated into a homogeneous output good. As is well known from these models, opening up an economy provides access to a larger pool of intermediate varieties and, hence, creates gains from trade through a positive external scale effect (that can be associated with amplified division of labor). Following Melitz (2003), we assume that producers in the differentiated goods industry are heterogeneous with respect to their productivity. As compared to a framework with homogeneous firms, the assumption of heterogeneous producers opens an additional channel through which countries can benefit from trade liberalization: changes in the composition of producers due to exit of the least productive competitors and self-selection of productive firms into export status.

While either effect is crucial for the welfare implications of trade liberalization, it is the adjustment at the extensive margin of firms (i.e., exit from/entry into the market as such) that is essential for our analysis. It is thus convenient to focus on compositional effects at the extensive margin, while disregarding selection into export status by setting trade costs equal to zero. Furthermore, we restrict our attention to trade between two economies, which are identical in all respects except of their labor market institutions. Labor market institutions are introduced by means of a real minimum wage which may differ between the two economies. If the real minimum wage, i.e., the nominal wage divided by the consumer price index, is binding, production faces a perfectly elastic labor supply as opposed to perfectly inelastic labor supply in the Ethier as well as the Melitz model. Clearly, with a binding real minimum wage, there exists a third channel through countries can benefit from trade liberalization: an increase in the

\footnotetext{
${ }^{3}$ See Kreickemeier and Nelson (2006); Meckl (2006) for extensions and modifications of Davis' framework which suggest the same conclusion as Davis (1998) with regard to linkages of foreign and domestic labor markets in open economies: more rigid labor markets abroad benefit domestic labor.
} 
employment rate. As pointed out in our analysis, this employment effect is closely related to and interacts with the other two sources of gains from trade.

Regarding the existence of cross-country spillovers of national labor market institutions, it is notable that international trade links the variable production costs of intermediate goods producers at home and abroad. With homogeneous producers (under diversified production and free trade), the minimum wage can only be binding in one country while full employment prevails in the other one. The reason is that if one of the two economies (say Europe) faces a higher minimum wage than the other economy (say, the US), intermediate goods producers in Europe are forced to exit, while at the same time new intermediate goods producers enter in the US. Intuitively, production shifts to the country that offers lower production costs. This adjustment process continues until all workers in the US are employed and US wages are driven up to the European minimum wage. As in Davis (1998), an increase in the binding real minimum wage therefore raises unemployment in Europe and props up wages in the US if firms are homogeneous.

However, if firms differ in their production costs due to heterogeneity in productivity, trade only equalizes the variable production costs of the marginal (i.e., the least productive) producers in the two economies. In this case, minimum wages can differ and still be binding in both countries as long as productivity differences of marginal firms compensate for the prevailing wage differences. As a consequence, country-specific minimum wages may lead to involuntary unemployment in both economies if firms differ in their productivity levels. Notably, if Europe raises its minimum wage, US workers need not benefit from it. The reason is that there are two counteracting effects. On the one hand, a higher minimum wage induces an efficiency loss and hence reduces aggregate world demand for intermediate goods. This hurts both economies and hence forces firms to exit in Europe and the US ceteris paribus. On the other hand, there is relocation of production of intermediate goods from Europe to the US in response to a relative rise of the European minimum wage. While both of these effects also exist in a model with homogeneous firms, the second effect is dampened with heterogeneous producers due to a decline of the marginal US firm's productivity (triggered by entry of new firms with low productivity) and an increase of the marginal European firm's productivity (triggered by exit of the least productive incumbent firms). As a consequence, the second (production relocation) effect does not necessarily compensate the first (aggregate demand) effect so that a higher European minimum wage may lower labor demand in Europe as well as the US. This indicates that negative spillover effects of an increase in labor market imperfections are possible in open economies if firms differ in their productivity levels and, hence, provides an intuition for the positive correlation between unemployment rates in Europe and the US as depicted in Figure 1.

The remainder of the paper is organized as follows. In Section 2, we set up the basic model 
structure and investigate the autarky equilibrium. In Section 3 we characterize the equilibrium of the open economy and compare the respective outcome with the autarky scenario. Section 4 provides a comparative static analysis to study the impact that an increase in the European minimum wage exhibits on employment and aggregate wage income in Europe and the US. In Section 5 we allow for international offshoring within multinational firms, in order to see whether and to what extent the insights from our analysis depend on the mode of firm organization. ${ }^{4}$ The last section concludes with a brief summary of the most important results.

\section{The closed economy}

\subsection{Basic model assumptions}

We consider a model with one homogeneous final good - used for consumption as well as investment - and a mass of differentiated intermediate goods. The economy under consideration is populated by $L$ workers, each supplying one unit of labor. The production technology in the final goods sector is CES and represented by

$$
Y=M^{-\frac{\eta}{\sigma-1}}\left(\int_{v \in V} q(v)^{\frac{\sigma-1}{\sigma}} d v\right)^{\frac{\sigma}{\sigma-1}}
$$

where $q(v)$ is the quantity of intermediate variant $v$ employed in the production of $Y, V$ is the set of available varieties with measure $M$, and $\sigma$ denotes the elasticity of substitution between variants of the intermediate. Parameter $\eta \in[0,1]$ is inversely related to the standard DixitStiglitz variety effect, which we will refer to as the "external scale effect", following Ethier (1982). In the borderline case of $\eta=1$, the variety or external-scale effect vanishes, and $Y$ has constant-returns to scale in both the levels and the number of varieties. In the case of $\eta=0$, we have the standard Dixit-Stiglitz case, where $Y$ exhibits increasing returns and is homogeneous of degree $\sigma /(\sigma-1)$ in the measure of varieties. The special cases of (i) $\eta=0$ and (ii) $\eta=1$ are respectively given by:

$$
Y=\left(\int_{v \in V} q(v)^{\frac{\sigma-1}{\sigma}} d v\right)^{\frac{\sigma}{\sigma-1}}, \quad Y=M^{\frac{1}{1-\sigma}}\left(\int_{v \in V} q(v)^{\frac{\sigma-1}{\sigma}} d v\right)^{\frac{\sigma}{\sigma-1}} .
$$

As will be discussed in detail in Subsection 2.3, a necessary (but not sufficient) condition for Walrasian stability of the equilibrium in the presence of minimum wages is that $\eta>0$.

\footnotetext{
${ }^{4}$ In this respect, our paper contributes to a well-established literature that addresses the role of labor market imperfections (typically associated with labor unions) for explaining the foreign investment decision of international producers (see, e.g., Skaksen and Sørensen, 2001; Lommerud, Meland, and Sørgard, 2003; Eckel and Egger, 2009). However, none of these studies looks at cross-border linkages in unemployment rates, which are at the heart of this paper's interest.
} 
Let us use $P$ to denote the price of the homogeneous final good and $p(v)$ to denote the price of intermediate variant $v$. Final goods producers choose $q(v)$ (for all $v$ ) in order to maximize their profits, $P Y-\int_{v \in V} p(v) q(v) d v$. Under perfect competition, the price of each intermediate good equals this good's marginal revenue product and profits of final goods producers are driven down to zero due to free market entry. Consequently, $P$ must fulfill the zero profit condition $P Y=\int_{v \in V} p(v) q(v) d v$ and hence it is given by a CES index of intermediate goods prices $P=\left[M^{-\eta} \int_{v \in V} p(v)^{1-\sigma} d v\right]^{1 /(1-\sigma)}$. Choosing final output as the numéraire and setting its price equal to unity, we can formulate the solution to the profit maximization problem of final goods producers in the following way:

$$
q(v)=\frac{Y}{M^{\eta}} p(v)^{-\sigma},
$$

with the latter characterizing demand for intermediate good variety $v$.

Intermediate goods are supplied by monopolistically competitive firms, with each firm producing a unique variety (and thus $M$ being equal to the mass of competitors). Output of an intermediate goods producer depends on labor input $l$ and labor productivity $\phi: q=\phi l$. Marginal production costs are given by $w / \phi$ with $w$ denoting a (real) minimum wage that is identical across firms and set by the government. Facing demand (2) and taking aggregate variables as given, intermediate goods producers maximize their profits by setting prices as a constant markup over marginal costs. This yields

$$
p(\phi)=\frac{\sigma w}{(\sigma-1) \phi}
$$

and concludes our brief discussion on profit maximization of intermediate goods producers, when taking their entry decision as given.

\section{$2.2 \quad$ Firm entry and aggregation}

Regarding firm entry, we apply a modified version of the Melitz (2003) framework and assume that the mass of potential entrants is exogenously given by parameter $N$. These potential entrants differ in their productivity levels $\phi$, with $G(\phi)$ denoting the cumulative distribution of productivity. Hence, entry reduces to a one-stage process and we obtain a static model with aggregate profits being strictly positive (see Do and Levchenko, 2009). In all other respects, the properties of the goods market variables in the static model variant are the same as those of the dynamic version in Melitz (2003).

In particular, for given aggregate variables, productivity of the marginal active firm - which exhibits the lowest productivity level that is consistent with non-negative profits - is determined 
by a zero cutoff profit condition. Assuming that the operation of an input firm requires the initial investment of one unit of final output, the respective condition reads ${ }^{5}$

$$
r\left(\phi^{*}\right)=\sigma
$$

where $\phi^{*}$ denotes the productivity level of the marginal firm (in short, marginal productivity) and $r\left(\phi^{*}\right)=\left(Y / M^{\eta}\right) p\left(\phi^{*}\right)^{1-\sigma}$ denotes revenues of this firm. Hence, the mass of active firms is determined as $M=N\left(1-G\left(\phi^{*}\right)\right)$. In order to obtain aggregate variables, we can characterize an average firm by the following condition: $P=M^{(1-\eta) /(1-\sigma)} p(\tilde{\phi})$. As discussed in Melitz (2003), the productivity level of the average firm (average productivity, in short), $\tilde{\phi}$, equals the weighted harmonic mean of the productivity levels of active producers, with relative outputs $q(\phi) / q(\tilde{\phi})$ serving as weights. The usefulness of this productivity average flows from the observation that aggregate revenues, $R$, and aggregate profits, $\Pi$, are the same in our model as they would be if the economy were populated by $M$ firms with identical productivity level $\tilde{\phi}: R=\operatorname{Mr}(\tilde{\phi})$ and $\Pi=M \pi(\tilde{\phi})$, with $\pi(\tilde{\phi})=r(\tilde{\phi}) / \sigma-1$. Final output is given by $Y=M^{(\sigma-\eta) /(\sigma-1)} q(\tilde{\phi})$, implying that $Y=M^{1-1 / \sigma} q(\tilde{\phi})$, if $\eta=0$, while $Y=M q(\tilde{\phi})$, if $\eta=1$.

To facilitate our analysis, we impose the by now standard assumption of Pareto-distributed productivity levels and consider $G(\phi)=1-\phi^{-k}$, where $k$ is the shape parameter of the Pareto distribution and the lower bound to productivity levels is normalized to unity (i.e., $\phi \geq 1$ ). The corresponding density function is given by $g(\phi)=k \phi^{-k-1} \cdot{ }^{6}$ Under the Pareto assumption, average productivity $(\tilde{\phi})$ is proportional to marginal productivity $\left(\phi^{*}\right)$ :

$$
\tilde{\phi}=\left(\frac{k}{k-\sigma+1}\right)^{\frac{1}{\sigma-1}} \phi^{*}
$$

where $k>\sigma-1$ is assumed in order to ensure that the productivity average has a finite positive value (see Baldwin, 2005). Furthermore, revenues of the average firm are proportional to revenues of the marginal firm, and they are constant:

$$
r(\tilde{\phi})=\left(\frac{\tilde{\phi}}{\phi^{*}}\right)^{\sigma-1} r\left(\phi^{*}\right)=\frac{k \sigma}{k-\sigma+1} .
$$

\subsection{Equilibrium in the closed economy}

In order to characterize the autarky equilibrium, let us first concentrate on productivity levels $\phi^{*}, \tilde{\phi}$, and the mass of firms $M$. Equilibrium values of these variables are determined by

\footnotetext{
${ }^{5}$ Notably, assuming that fixed costs are equal to unity is not essential for the results of interest here. It simply helps economizing on notation.

${ }^{6}$ Besides its attractiveness in terms of analytical tractability, the Pareto assumption entertains considerable empirical support. For instance, Del Gatto, Mion, and Ottaviano (2006, p. 17) conclude from a firm-level analysis in European industries that "Pareto is a fairly good approximation of the underlying productivity distributions."
} 
the following three equations. The first one is the cutoff productivity condition (CPC), which determines a relationship between the mass of competitors $M$ and cutoff (or marginal) productivity $\phi^{*}: M=N\left(1-G\left(\phi^{*}\right)\right)=N\left(\phi^{*}\right)^{-k}$. The second one is the average productivity condition (APC), which links marginal and average productivity, according to (5). The third one can be deduced from profit-maximizing behavior of firms and characterizes those combinations of marginal productivity $\phi^{*}$ and the mass of competitors $M$ that are consistent with this behavior. This profit maximization condition (PMC) can be determined by linking $r(\tilde{\phi})=\left(Y / M^{\eta}\right) p(\tilde{\phi})^{1-\sigma}$ and $Y=\operatorname{Mr}(\tilde{\phi})$ (which gives $\left.p(\tilde{\phi})=M^{(1-\eta) /(\sigma-1)}\right)$ with (3), (5):

$$
\frac{w \sigma}{\sigma-1}\left(\frac{k}{k-\sigma+1}\right)^{\frac{1}{1-\sigma}} \frac{1}{\phi^{*}}=M^{\frac{1-\eta}{\sigma-1}}
$$

Figure 2 illustrates the three conditions and the equilibrium values of $\phi^{*}, \tilde{\phi}$, and $M$ graphically. (We use subscript $a$ to refer to autarky, there.) For drawing the two loci in the right panel of this figure, we have imposed two additional assumptions. First, we assume that $N$ is sufficiently large in order to ensure an intersection of the two downward sloping curves at $\phi^{*}>1$ in the left panel of Figure 2. Otherwise, the equilibrium would be characterized by $M=N$ and $\phi^{*}=1$, and hence all potential producers would be active, irrespective of their productivity levels. We exclude this case in order to make our results comparable to those in Melitz (2003), who considers an unbounded mass of potential entrants. Second, (Walrasian) stability of the equilibrium requires $k(1-\eta)<(\sigma-1)$. This ensures that the CPC locus intersects the PMC locus from above. The respective condition is fulfilled if the external scale effect is not too large, i.e., $\eta$ is sufficiently close to unity. For an intuition about the latter, note that a bigger mass of competitors exhibits two effects on firm entry. On the one hand, it raises final goods output, thereby increasing demand for intermediate goods and thus rendering firm entry more attractive. This provides a source of instability, as a larger number of firms stimulates subsequent entry. Notably, this (aggregate demand) effect is the stronger, the larger the external scale effect. On the other hand, a bigger $M$ implies more competition among intermediate goods producers for a given level of final goods output and, hence, a negative impact on demand for each variety. The latter stabilizes the equilibrium in the sense that an increase in the mass of competitors lowers the incentive for further firm entry. From eq. (2) we can deduce that the latter effect is relatively strong if the external scale effect is weak, and it dominates the positive aggregate demand effect if $\eta>(k-\sigma+1) / k .^{7}$ Summing up, if the mass of potential entrants is sufficiently large and the external scale effect is not too strong, then a unique and stable autarky equilibrium exists. In

\footnotetext{
${ }^{7}$ Two remarks are in order here. First, it is clear that either of these effects materializes in any monopolistic competition model. However, in other models there exists an additional stabilizing force by means of increasing factor prices in response to firm entry. This adjustment channel has been closed in our model by considering a binding real minimum wage which constrains the parameter domain supporting a stable equilibrium. Second, the
} 
the borderline case of no external scale effects, i.e., at $\eta=1$, the PMC locus becomes horizontal and the existence of a stable equilibrium is guaranteed. ${ }^{8}$

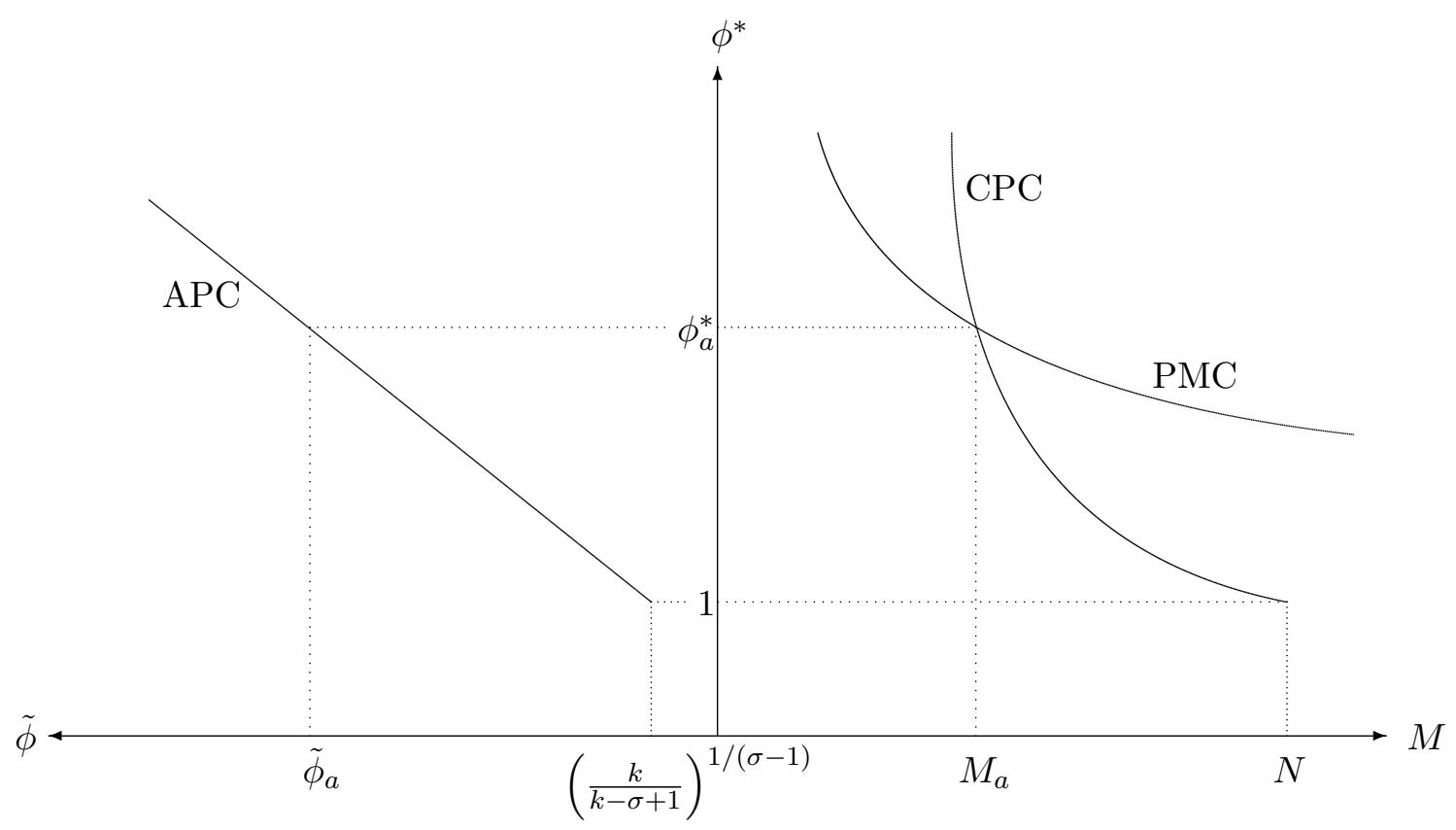

Figure 2: Equilibrium in the closed economy

A higher minimum wage, $w$, renders production of firms with low productivity levels unattractive and thus raises marginal productivity $\phi^{*}$ and, by virtue of (5), also average productivity $\tilde{\phi}$. At the same time, the mass of active firms declines because of the negative link between $\phi^{*}$ and $M$ that follows from CPC. Graphically, an increase in the minimum wage shifts the PMC locus outwards, with the respective productivity and firm number effects following from Figure 2. A larger pool of potential entrants, $N$, shifts the CPC locus outwards with a positive effect on the mass of active firms $M$. If there are external scale effects, i.e., $\eta<1$, the higher mass of active firms induces higher demand for all intermediate goods. As a consequence, market entry

minimum level of $\eta$ that supports existence of a stable equilibrium increases in $k$. The reason is that a higher $k$ lowers the elasticity of marginal productivity $\phi^{*}$ with respect to $M$ (in absolute terms). A given increase in $M$ leads to a smaller reduction of $\phi^{*}$ (and, hence, $\tilde{\phi}$ ) at higher $k$, thereby aggravating the positive aggregate demand effect of a greater mass of $M$ as described above. The latter amplifies the destabilizing forces in the model ceteris paribus and, hence, requires $\eta$ to increase in order to support a stable equilibrium at higher $k$.

${ }^{8}$ It is notable that, in contrast to Melitz (2003), we did not make use of the zero cutoff profit condition in (4) and (6) for characterizing the equilibrium in Figure 2. However, this condition will play a role for determining equilibrium output and employment in autarky (see below). 
now becomes attractive for firms with relatively low productivity levels, implying that $\phi^{*}$ and $\tilde{\phi}$ decline. In the borderline case of $\eta=1$, the increase in $M$ does not stimulate demand for intermediate goods so that $\phi^{*}$ and $\tilde{\phi}$ remain unaffected by the increase in the mass of potential entrants, $N$.

To facilitate a comparison between autarky and the trade equilibrium in the next section, it is useful to explicitly solve for aggregate product market variables. Straightforward calculations yield

$$
\begin{gathered}
\phi_{a}^{*}=\left(\frac{\sigma-1}{w \sigma}\right)^{\frac{\sigma-1}{k(1-\eta)-\sigma+1}}\left(\frac{k N^{1-\eta}}{k-\sigma+1}\right)^{\frac{1}{k(1-\eta)-\sigma+1}} \\
\tilde{\phi}_{a}=\left(\frac{\sigma-1}{w \sigma}\right)^{\frac{\sigma-1}{k(1-\eta)-\sigma+1}}\left[\left(\frac{k}{k-\sigma+1}\right)^{\frac{k}{\sigma-1}} N\right]^{\frac{1-\eta}{k(1-\eta)-\sigma+1}}
\end{gathered}
$$

and

$$
M_{a}=\left(\frac{w \sigma}{\sigma-1}\right)^{\frac{k(\sigma-1)}{k(1-\eta)-\sigma+1}}\left(\frac{k-\sigma+1}{k N^{(\sigma-1) / k}}\right)^{\frac{k}{k(1-\eta)-\sigma+1}} .
$$

Total output of final goods can now be determined by combining the adding-up condition $Y=$ $\operatorname{Mr}(\tilde{\phi})$ with eqs. (6) and (10). This yields

$$
Y_{a}=\left(\frac{w \sigma}{\sigma-1}\right)^{\frac{k(\sigma-1)}{k(1-\eta)-\sigma+1}}\left(\frac{k-\sigma+1}{k N^{(\sigma-1) / k}}\right)^{\frac{k}{k(1-\eta)-\sigma+1}} \frac{k \sigma}{k-\sigma+1}
$$

and completes our discussion of the goods market equilibrium in autarky.

For characterizing the labor market outcome, note that the constant markup-pricing rule establishes a proportional relationship between revenues $p(\phi) q(\phi)$ and labor cost expenditures $w l(\phi) \sigma /(\sigma-1)$ at the firm level: $p(\phi) q(\phi)=w l(\phi) \sigma /(\sigma-1)$. Furthermore, let us denote the unemployment rate by $u$ and employment of the average firm by $l(\tilde{\phi})$. Then, due to the adding-up condition, employment in all firms, $\operatorname{Ml}(\tilde{\phi})$, must equal the total employed labor force, $(1-u) L$. Accordingly, total labor cost expenditures (which are equal to aggregate labor income, $W)$ are proportional to total revenues, i.e., $W=\operatorname{Mr}(\tilde{\phi})[(\sigma-1) / \sigma]$, with $\operatorname{Mr}(\tilde{\phi})=Y$ and $W \equiv(1-u) L w$. Hence, the equilibrium values of aggregate labor income and unemployment are given by

$$
W_{a}=\left(\frac{w \sigma}{\sigma-1}\right)^{\frac{k(\sigma-1)}{k(1-\eta)-\sigma+1}}\left(\frac{k-\sigma+1}{k N^{1-\eta}}\right)^{\frac{k}{k(1-\eta)-\sigma+1}} \frac{k(\sigma-1)}{k-\sigma+1}
$$

and

$$
u_{a}=1-\left(\frac{w \sigma}{\sigma-1}\right)^{\frac{k(\sigma-1)}{k(1-\eta)-\sigma+1}}\left(\frac{k-\sigma+1}{k N^{1-\eta}}\right)^{\frac{k}{k(1-\eta)-\sigma+1}} \frac{k(\sigma-1)}{L w[k-\sigma+1]}
$$


respectively, according to (11).

For the minimum wage to be binding, i.e., for $u_{a}>0$, the pool of workers $L$ needs to be sufficiently large. This is assumed from now on. A higher $L$ raises unemployment $u$ and leaves aggregate wage income $W$ unaffected. With constant markup pricing, aggregate wage income is proportional to total output of final goods, which has been shown to be independent of $L$. With a binding minimum wage, an increase in $L$ reduces employment rate $(1-u)$ proportionally, thereby leaving aggregate employment unchanged. However, from this result it should not be deduced that the unemployment rate exhibits a country-size pattern. To the extent that larger economies also have a larger pool of potential entrants, $N$, the model is consistent with the empirical observation that unemployment may be a problem of large as well as small economies. Beyond that, a higher minimum wage lowers total labor income $W$ and worsens the unemployment problem, if $k(1-\eta)<\sigma-1$. This is intuitive, as a higher minimum wage reinforces the labor market imperfection and therefore renders the market outcome less efficient. This completes our discussion of the autarky equilibrium.

\section{The open economy}

We now assume that there are two countries whose economies are of the type described in the previous section. The two countries are fully identical except for the size of minimum wages. The minimum wage is binding in both economies and we associate the country with the higher minimum wage with Europe (superscript $E$ ) and the other one with the US (superscript $A$ ) in order to capture the empirical fact that labor market imperfections are more severe in Europe than in the US. Workers are immobile and firms can serve the foreign market only through exports, while the consequences of offshoring of production within vertical multinational firms are discussed in an extension to our model (see Section 5). Furthermore, to facilitate our analysis, we abstract from any trade impediments (for final goods as well as intermediates) and assume that all intermediate goods producers are exporters. ${ }^{9}$ Accordingly, $Y$ and $P$ are identical for all firms, irrespective of the country in which they produce and, hence, the zero cutoff profit conditions, which are given by $r_{E}\left(\phi_{E}^{*}\right)=\sigma$ and $r_{A}\left(\phi_{A}^{*}\right)=\sigma$, respectively, result in

$$
\frac{\phi_{E}^{*}}{\phi_{A}^{*}}=\frac{w_{E}}{w_{A}},
$$

\footnotetext{
${ }^{9}$ It is an empirical stylized fact that there is self-selection into export status and that exporters exhibit higher levels of productivity than non-exporters (see e.g. Bernard and Jensen, 1995, 1999). However, accounting for exporting as well as non-exporting firms in the model would only complicate our analysis without changing the main insights.
} 
which is strictly larger than unity, if $w_{E}>w_{A}$. Eqs.(3) and (14) imply $p_{E}\left(\phi_{E}^{*}\right)=p_{A}\left(\phi_{A}^{*}\right)$ as well as $p_{E}\left(\tilde{\phi}_{E}\right)=p_{A}\left(\tilde{\phi}_{A}\right)$, where $\tilde{\phi}_{i}, i=A, E$ is defined analogously to the closed economy case and, hence, it is proportional to the marginal productivity level, according to (5). ${ }^{10}$ As noted in previous contributions on the matter, in the open economy it is necessary to distinguish between the average productivity of domestic firms, $\tilde{\phi}_{i}$, and the average productivity in the market, $\tilde{\phi}_{i t}$, with the latter accounting for domestic production as well as the imports of foreign producers. This average market productivity is defined in a way to ensure that $P=M_{t}^{(1-\eta) /(1-\sigma)} p_{i}\left(\tilde{\phi}_{i t}\right)$ holds, with $M_{t} \equiv M_{A}+M_{E}$ denoting the total mass of intermediate goods available at the market. As extensively discussed in Egger and Kreickemeier (2009), the two averages $\tilde{\phi}_{i t}$ and $\tilde{\phi}_{i}$ are identical only if the negative lost-in-transit effect (caused by goods melting away en route when international transactions are subject to iceberg transport costs) and the positive exportselection effect (caused by selection of only the firms with relatively high productivity levels into exports status) are of the same size. Since we abstract from any trade impediments and all firms export in this paper, $\tilde{\phi}_{i t}=\tilde{\phi}_{i}$ must hold.

With the characterization of the average firm at hand, we can now proceed to determine the goods market equilibrium in the open economy. For this purpose, we can again employ the cutoff productivity condition (CPC), the average productivity condition (APC), and the profit maximization condition (PMC) to solve for the equilibrium values of $M_{i}, \phi_{i}^{*}$, and $\tilde{\phi}_{i}$. While the CPC and APC conditions are the same as in the closed economy, the specification of PMC has to be adjusted, because in the open economy the mass of domestically produced intermediates is smaller than the total mass of available intermediates. By virtue of (14), we have $M_{t}=\left[1+\left(w_{i} / w_{j}\right)^{k}\right] M_{i}, i \neq j$ and, hence, the country-specific PMC in the open world economy is given by

$$
\frac{w_{i} \sigma}{\sigma-1}\left(\frac{k}{k-\sigma+1}\right)^{\frac{1}{1-\sigma}} \frac{1}{\phi_{i}^{*}}=\left[\left(1+\left(\frac{w_{i}}{w_{j}}\right)^{k}\right) M_{i}\right]^{\frac{1-\eta}{\sigma-1}} .
$$

Figure 3 depicts the three conditions and the equilibrium values of $M_{i}, \phi_{i}^{*}$, and $\tilde{\phi}_{i}$. To facilitate the comparison of the closed and the open economy cases, we also display the autarky equilibrium. From inspection of the figure it is immediate that a movement from autarky to free trade reduces the marginal and average productivity levels, while it increases the mass of active intermediate goods producers with headquarters in country $i$. This is in sharp contrast to the Melitz framework and, hence, calls for further discussion.

\footnotetext{
${ }^{10}$ With constant markup pricing, $p_{E}\left(\phi_{E}^{*}\right)=p_{A}\left(\phi_{A}^{*}\right)$ also implies that variable production costs of the two marginal firms are equalized in the open economy. This, however, is not true for the closed economy and, hence, the ratio of cutoff productivity levels does not equal the ratio of minimum wages under autarky; see eqs. (8) and (14).
} 
In Melitz' original framework, the most productive firms start exporting in the open economy and production expands at the intensive margin ceteris paribus. This raises nominal wages and, hence, forces the least productive non-exporters to exit. As a consequence, the mass of domestic producers shrinks and marginal productivity increases if a country opens up to trade. In our model, labor supply is perfectly elastic at the mandated real minimum wage and, hence, the nominal wage rate is uncoupled from changes in labor demand. An increased mass of available intermediate varieties $M$ in the open economy leads to a fall in the price index (if $\eta<1$ ) and, due to a constant real minimum wage, provokes a decline in the nominal wage rate. This allows less productive firms to enter in the open economy and induces a decline in the cutoff productivity level when a country opens up to trade. ${ }^{11}$

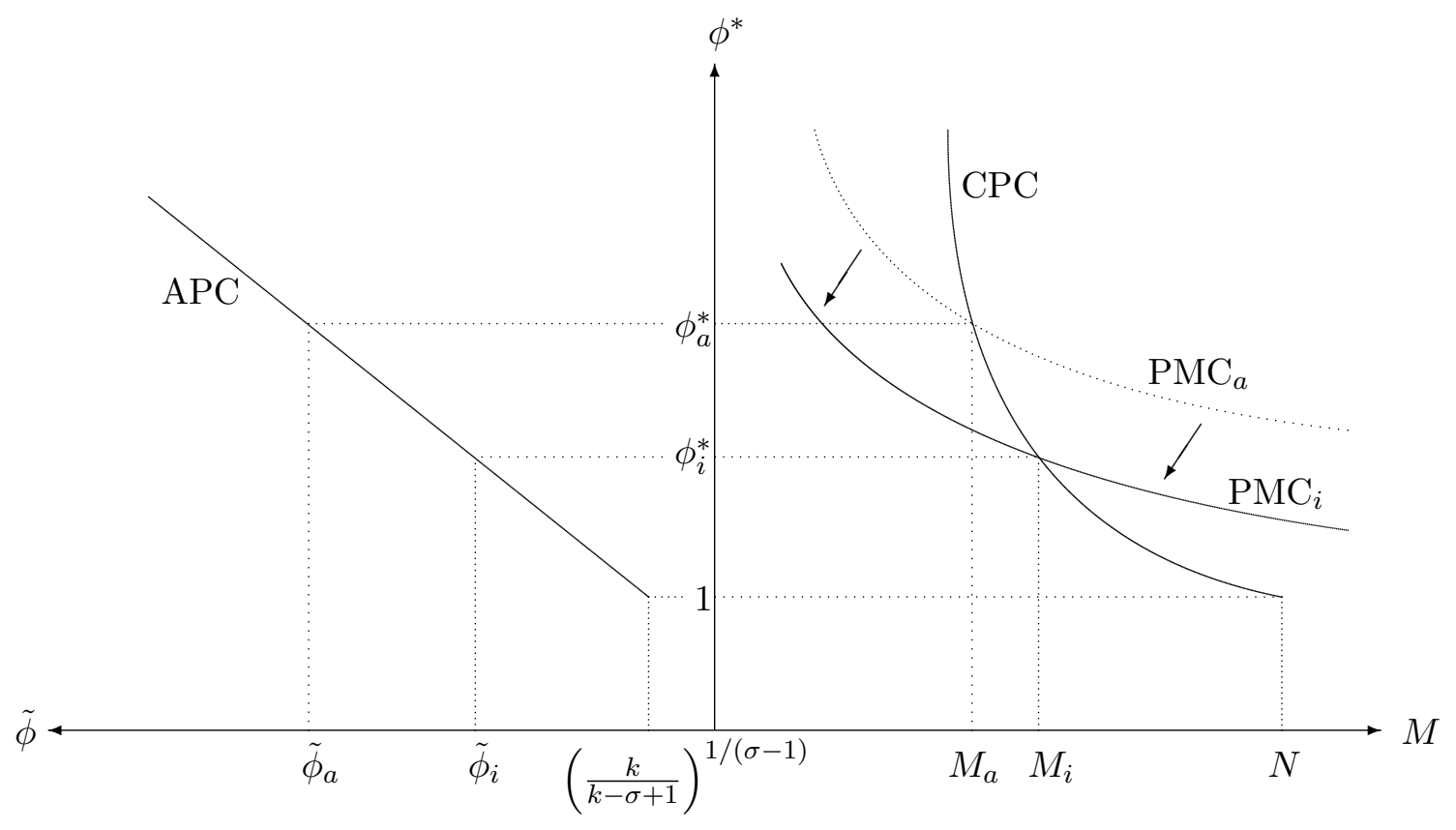

Figure 3: Equilibrium in the open economy

Using the three conditions $\mathrm{CPC}, \mathrm{APC}$, and $\mathrm{PMC}_{i}$, we can explicitly solve for the equilibrium values of $\phi^{*}, \tilde{\phi}$, and $M$ in the open economy. This gives

$$
\phi_{i}^{*}=\left(\frac{\sigma-1}{w_{i} \sigma}\right)^{\frac{\sigma-1}{k(1-\eta)-\sigma+1}}\left(\frac{k N^{1-\eta}}{k-\sigma+1}\right)^{\frac{1}{k(1-\eta)-\sigma+1}}\left[1+\left(\frac{w_{i}}{w_{j}}\right)^{k}\right]^{\frac{1-\eta}{k(1-\eta)-\sigma+1}},
$$

\footnotetext{
${ }^{11}$ In the borderline case of $\eta=1$, the higher mass of active firms in the open economy does not affect the price index so that the nominal wage rate stays constant. As a consequence, the mass of local producers does not change in response to trade liberalization.
} 


$$
\tilde{\phi}_{i}=\left(\frac{\sigma-1}{w_{i} \sigma}\right)^{\frac{\sigma-1}{k(1-\eta)-\sigma+1}}\left[\left(\frac{k}{k-\sigma+1}\right)^{\frac{k}{\sigma-1}} N\right]^{\frac{1-\eta}{k(1-\eta)-\sigma+1}}\left[1+\left(\frac{w_{i}}{w_{j}}\right)^{k}\right]^{\frac{1-\eta}{k(1-\eta)-\sigma+1}}
$$

and

$$
M_{i}=\left(\frac{w_{i} \sigma}{\sigma-1}\right)^{\frac{k(\sigma-1)}{k(1-\eta)-\sigma+1}}\left(\frac{k-\sigma+1}{k N^{(\sigma-1) / k}}\right)^{\frac{k}{k(1-\eta)-\sigma+1}}\left[1+\left(\frac{w_{i}}{w_{j}}\right)^{k}\right]^{\frac{k(1-\eta)}{\sigma-1-k(1-\eta)}}
$$

Furthermore, noting that revenues of the average firms in $A$ and $E$ do not differ and that these revenues are the same in the open and the closed economy cases, output of final goods can easily be determined by multiplying the right-hand side of (6) by $M_{i}$. By virtue of (18), we obtain

$$
Y_{i}=\left(\frac{w_{i} \sigma}{\sigma-1}\right)^{\frac{k(\sigma-1)}{k(1-\eta)-\sigma+1}}\left(\frac{k-\sigma+1}{k N^{(\sigma-1) / k}}\right)^{\frac{k}{k(1-\eta)-\sigma+1}} \frac{k \sigma}{k-\sigma+1}\left[1+\left(\frac{w_{i}}{w_{j}}\right)^{k}\right]^{\frac{k(1-\eta)}{\sigma-1-k(1-\eta)}},
$$

which is larger than the respective output level in autarky (see (11)), provided that $k(1-\eta)<$ $\sigma-1$. Since output increases in both economies, it is immediate that world-wide final goods production must also be higher in the open than in the closed world economy.

With these insights at hand, we can now pursue the analysis in the closed economy step by step to determine aggregate labor income, $W_{i}=\left(1-u_{i}\right) L w_{i}$, and the unemployment rate, $u_{i}$. In particular, we can make use of the insight that constant markup pricing gives rise to $\left(1-u_{i}\right) L_{i} w_{i}=[(\sigma-1) / \sigma] M_{i} r_{i}\left(\tilde{\phi}_{i}\right)$, in order to solve explicitly for the two variables of interest. Straightforward calculations yield

$$
W_{i}=\left(\frac{w_{i} \sigma}{\sigma-1}\right)^{\frac{k(\sigma-1)}{k(1-\eta)-\sigma+1}}\left(\frac{k-\sigma+1}{k N^{1-\eta}}\right)^{\frac{k}{k(1-\eta)-\sigma+1}} \frac{k(\sigma-1)}{k-\sigma+1}\left[1+\left(\frac{w_{i}}{w_{j}}\right)^{k}\right]^{\frac{k(1-\eta)}{\sigma-1-k(1-\eta)}}
$$

and

$$
u_{i}=1-\left(\frac{w_{i} \sigma}{\sigma-1}\right)^{\frac{k(\sigma-1)}{k(1-\eta)-\sigma+1}}\left(\frac{k-\sigma+1}{k N^{1-\eta}}\right)^{\frac{k}{k(1-\eta)-\sigma+1}} \frac{k(\sigma-1)}{L w_{i}[k-\sigma+1]}\left[1+\left(\frac{w_{i}}{w_{j}}\right)^{k}\right]^{\frac{k(1-\eta)}{\sigma-1-k(1-\eta)}}
$$

Since revenues of the average firm do not change when a country moves from autarky to trade, it follows from Figure 3 that aggregate labor income rises due to the increase in the mass of local producers $M_{i}$. Furthermore, with the minimum wage being binding in the closed as well as the open economy, the increase in aggregate labor income must be accompanied by a fall in the unemployment rate. These positive labor market implications are well in line with the finding for the competitive labor market model in Melitz (2003), where a movement from autarky to trade raises the demand for labor and thus leads to higher real wages. 
One further remark is in order here. While the focus of our analysis is on the labor market effects of trade liberalization, it is nonetheless possible (and probably interesting) to derive the respective welfare implications. Since there is only one final good in our model, total income $I_{i}$ can be used as a suitable utilitarian welfare measure for country $i=A, E$. $I_{i}$ is given by the sum of aggregate labor income, $W_{i}=[(\sigma-1) / \sigma] M_{i} r_{i}\left(\tilde{\phi}_{i}\right)$, and aggregate profits of domestic firms at unitary fixed costs, $\Pi_{i} \equiv M_{i}\left[r_{i}(\tilde{\phi}) / \sigma-1\right]$. With $r_{i}(\tilde{\phi})$ being constant according to (6), it follows directly that total income $I_{i}$ is proportional to $M_{i}$ and thus higher in the open than the closed economy. Hence, there are gains from trade in our setting. While the existence of welfare gains in a heterogeneous firms model is not new, it is notable that the source of these gains differs conceptually from those in Melitz (2003) where the increase in productivity levels is a key source of gains from trade. In our model, both the marginal and the average productivity level need to decline, if a country opens up to trade. However, aggregate employment expands due to entry of less productive firms, thereby reducing the negative consequences of labor market imperfection. ${ }^{12}$

\section{Minimum wages in the open economy}

In the previous section, we have characterized the equilibrium in the open economy for two countries that differ in their minimum wages. Furthermore, we have seen that, irrespective of the level of minimum wages, both countries benefit from the opening up to trade. However, the analysis so far has not provided any insights on how variations in one country's minimum wage affect the other economy. These cross-country linkages are at the heart of interest in the subsequent comparative-static analysis.

Starting point is an equilibrium in the open economy as characterized in Section 3. Now hypothesize that Europe raises its minimum wage from $w_{E}^{0}$ to $w_{E}^{1}$. Similar to the closed economy case, this shifts the European PMC locus outwards in Figure 3 and thus induces exit of local producers, i.e., $M_{E}$ declines. The intuition behind this effect is that an increase in the minimum wage reduces revenues of European firms, thereby rendering it unattractive for the marginal producer in the benchmark equilibrium to stay active. At the same time, $\phi_{E}^{*}$ and $\tilde{\phi}_{E}$ increase - as they are linked to $M_{E}$ through CPC and APC. While these effects are well understood from the closed economy case, there is a crucial difference between the two scenarios. A fall in

\footnotetext{
${ }^{12}$ Clearly, aside from the productivity and the employment effects, there are also welfare gains due to the access to foreign intermediates and hence a stronger division of labor in the open economy. As it is well established in new trade theory, such welfare gains depend crucially on the existence of external scale effects (see Ethier, 1982; Markusen, 1989). However, external scale effects are also elementary for welfare gains through positive employment effects, which can only materialize if the mass of local firms increases (see the above discussion).
} 
$M_{E}$ reduces the overall mass of available intermediate varieties $M_{t}$ in the open economy, with negative consequences for the US if external scale effects are in play, i.e., if $\eta<1$.

With external scale effects, a reduction in the mass of available intermediate varieties in Europe lowers demand for varieties produced in the US. Hence, the higher minimum wage in Europe triggers exit of the least productive firms and thus leads to a higher marginal and average productivity level in the US, see (15). Graphically, the increase in $w_{E}$ shifts the $\mathrm{PMC}_{A}$ locus outwards with positive effects on $\phi_{A}^{*}$ and $\tilde{\phi}_{A}$ and a negative impact on $M_{A}$. The latter is an immediate implication of firm heterogeneity, which dampens firm exit in Europe as well as firm entry in the US. Due to this, the negative efficiency effect of a higher European minimum wage dominates the positive relocation effect, implying that the mass of US producers declines on net. Furthermore, since both the employment rate $1-u_{i}$ and aggregate wage income $W_{i}$ are proportional to the mass of local producers, it is immediate that a higher minimum wage in Europe harms US workers. Put differently, Europe can export part of the costs of a higher minimum wage to the US labor market in the open world economy. This differs from the respective conclusion of the analysis in Davis (1998) but motivates a positive correlation between the unemployment rates in Europe and the US as in Figure 1.

\section{Labor market linkages under offshoring of intermediate goods production}

In the previous analysis, intermediate goods were tradable but it was not possible for firm owners in one country to offshore their production to the other economy if it was cheaper to do so. In this section, we relax this assumption and study the incentives of firms in the more constrained labor market (referred to as Europe, $E$ ) to offshore their production of intermediate goods within a multinational organization to the relatively less constrained labor market (referred to as the US, $A$ ) without changing the country headquarters are located in. Hence, profits accrue to the same country with offshoring as with integrated home production. The concept and incentive of offshoring in this model is similar to the one of unbundling of production in models with vertical multinational enterprises (see Helpman, 1984; Markusen, 2002), except that firms are heterogeneous here and offshoring requires producing with the firm-specific technology abroad.

Clearly, if there were no costs to offshoring, firms would always produce in the country with lower wages. As a consequence, only one country's minimum wage could be binding and labor market linkages would be the same as in a model with homogeneous firms. In this case, an increase in the minimum wage of Europe would prop up US wages, similar to Davis (1998). So, let us generally focus on the case where offshoring invokes an investment of $f$ units of final 
output in order to establish a production facility abroad. It is convenient (yet not crucial for our results) to assume that $f=1$ in order to keep notation simple. In this case, firms that shift production have to pay twice the fixed costs of exporters.

Let us consider a minimum wage differential that is sufficiently small to ensure that not all European firms engage in offshoring. Then, the marginal producers in the two countries are exporters and revenues of the marginal firms do not differ from those in the pure exporter scenario discussed in Sections 3 and 4. Hence, productivity levels of the marginal producers in the two economies are linked to the minimum wage ratio according to (14), provided that the minimum wage remains binding in both economies, which is assumed throughout the subsequent analysis. Furthermore, the marginal offshoring firm in the high-minimum-wage country (indicated by superscript $o$ ) is characterized by the indifference condition, $r_{A}\left(\phi_{E}^{o}\right) / \sigma-1=r_{E}\left(\phi_{E}^{o}\right) / \sigma$, which, accounting for $r_{A}(\phi)=\left(w_{E} / w_{A}\right)^{\sigma-1} r_{E}(\phi)$, can be explicitly solved for $r_{E}\left(\phi_{E}^{o}\right)$. Combining the resulting expression with the zero cutoff profit condition for country $E$ and denoting the share of offshoring firms by $\chi \equiv\left(\phi_{E}^{o} / \phi_{E}^{*}\right)^{-k}$, we obtain

$$
\chi=\left[\left(\frac{w_{E}}{w_{A}}\right)^{\sigma-1}-1\right]^{\frac{k}{\sigma-1}} .
$$

Intuitively, the share of European offshoring firms rises with the minimum wage differential $w_{E} / w_{A}$. Furthermore, the formal condition for only part of European firms engaging in offshoring (i.e., $\chi<1$ ) is given by $w_{E} / w_{A}<2^{1 /(\sigma-1)} \equiv \bar{\omega}$.

In a next step, we have to determine whether the productivity of the average domestic firm is still equal to the average market productivity with offshoring as in the pure exporter scenario. Defining average market productivity $\tilde{\phi}_{i t}$ in a way to ensure $P=M_{t}^{(1-\eta) /(1-\sigma)} p_{i}\left(\tilde{\phi}_{i t}\right)$, it follows from the respective discussion in Section 3 that $\tilde{\phi}_{i t}>\tilde{\phi}_{i}$. The reason is that with $w_{E}>w_{A}$ only the most productive European firms invest and offshore their production to the US. Hence, there is a positive selection effect, which implies that the average productivity in the market is larger than the average productivity of domestic producers. As formally shown in the Appendix, the relationship between $\tilde{\phi}_{i t}$ and $\tilde{\phi}_{i}$ is determined by

$$
\tilde{\phi}_{i t}=\left[1+\frac{\chi}{1+\left(w_{E} / w_{A}\right)^{k}}\right]^{\frac{1}{\sigma-1}} \tilde{\phi}_{i} .
$$

From eqs. (22) and (23), it follows that $w_{E}=w_{A}$ implies $\chi=0$ and thus, in line with the pure exporter scenario, $\tilde{\phi}_{i t}=\tilde{\phi}_{i}$. In contrast, $w_{E} / w_{A} \in(0, \bar{\omega})$ yields $\chi \in(0,1)$ and therefore $\tilde{\phi}_{i t}>\tilde{\phi}_{i}$, which confirms our intuition above. Differentiating the expression in brackets of (23), we can further conclude that the ratio of the average market productivity and the average productivity of domestic firms, $\tilde{\phi}_{i t} / \tilde{\phi}_{i}$, increases monotonically in the cross-country differential of minimum 
wages, $w_{E} / w_{A}$. Indeed, an increase in the minimum wage differential renders it more attractive for European firms to bear the additional fixed costs of offshoring to the US. Since offshoring firms need to be more productive than average exporters (in either country) and since these firms can produce at lower costs and thus expand their output after offshoring, the increase of the minimum wage differential raises the productivity differential $\tilde{\phi}_{i t} / \tilde{\phi}_{i}$ in the US as well as Europe.

With the average market productivity deviating from the average productivity of domestic producers, the modified zero cutoff profit condition for the US under offshoring is different from the respective condition in the pure exporter scenario. We denote the new condition by $\mathrm{PMC}_{A}^{\prime}$ which determines again a negative relationship between marginal productivity $\phi_{i}^{*}$ and firm number $M_{i}$ as long as $\eta<1$ :

$$
\frac{w_{i} \sigma}{\sigma-1}\left(\frac{k}{k-\sigma+1}\right)^{\frac{1}{1-\sigma}}\left[1+\frac{\chi}{1+\left(w_{E} / w_{A}\right)^{k}}\right]^{\frac{1}{1-\sigma}} \frac{1}{\phi_{i}^{*}}=\left[\left(1+\left(\frac{w_{i}}{w_{j}}\right)^{k}\right) M_{i}\right]^{\frac{1-\eta}{\sigma-1}},
$$

where $i \neq j$. Comparing eq. $\left(15^{\prime}\right)$ with eqs. (7) and (15), we find that the PMC locus shifts southwest in response to an economy's opening up to trade, as in the pure exporter scenario. However, with offshoring of production, the respective shift of PMC in Figure 3 is more pronounced and hence the increase in the mass of firms $M_{i}$ and the decline in productivity levels $\phi_{i}^{*}, \tilde{\phi}_{i}$ is stronger than in the pure exporter scenario. The reason is that the gains from trade are higher if European firms can make use of cheaper foreign labor costs through offshoring to the US. This further stimulates demand for intermediate goods, implying that the open economy is characterized by a larger mass of producers with offshoring than without it. This additional demand stimulus does not rely on the existence of external scale effects. Hence, the PMC-locus in the open economy with offshoring lies below the respective locus of the closed economy, even if $\eta=1$.

Similar to the pure exporter scenario, the surge in firm entry ceteris paribus leads to higher aggregate labor income and to a lower unemployment rate in the two economies. With respect to the US labor market, this effect is reinforced by offshoring of the most productive European firms, so that both aggregate labor income $W_{A}$ and the employment rate $1-u_{A}$ are unambiguously higher in the open than in the closed economy. In Europe, the positive effect of higher firm entry is counteracted by offshoring of European producers with negative implications for domestic employment and aggregate labor income. In general, it is not clear which of the two effects dominates. Hence, with minimum wages being higher in Europe than in the US, it is possible that European workers are worse off in the open than in the closed economy. European workers would benefit from opening up the economy, if $w_{E}$ were sufficiently close to $w_{A}$. Then, only a small fraction of European producers would be willing to bear the additional investment cost 
of offshoring to the US. Conversely, if $w_{E} / w_{A} \rightarrow \bar{\omega}$, then the share of European non-offshoring firms would approach zero and, hence, all European workers would become unemployed.

As a final element of our analysis, let us take a closer look at the labor market linkages in an open economy with offshoring. For this purpose, we investigate how an increase in the European minimum wage influences the labor market outcome in the US. There are two counteracting effects. On the one hand, US workers lose from an external scale effect, if $\eta<1$. In general, a higher European minimum wage reduces world output and demand, and thus leads to exit of intermediate goods producers in both economies. On the other hand, US workers benefit from a larger share of European firms that shift production across the Atlantic. In the borderline case of $\eta=1$, only the second effect materializes and, similar to Davis (1998), a higher degree of labor market imperfection in Europe exhibits a positive impact on the US labor market. If, however, $\eta<1$, this result needs not hold any longer. If the external scale effect is sufficiently strong, a negative impact on US workers is possible. In broad terms, we can therefore conclude that offshoring of production lowers the positive correlation between European and US unemployment rates, but it does not (necessarily) destroy it.

\section{Concluding remarks}

This paper develops a model of two large economies with heterogeneous intermediate goods producers and imperfect labor markets, due to country-specific real minimum wages. Within this setting, we show that the existence of minimum wages affects the channels through which gains from trade materialize. In the formulation of Melitz and other authors who rely on the assumption of an inelastic labor supply, both an increase in the mass of available varieties and an increase in the marginal productivity, which improves the composition of firms, are the driving forces behind the welfare gains from trade liberalization. In our model, trade reduces the price index (relative to other prices), quite similar to a model with perfect labor markets. However, with a constant real minimum wage, the price reduction leads to a fall in the nominal wage and thus renders entry of firms with low productivity levels attractive. This worsens the composition of firms and leads to a fall in the marginal productivity level, an effect which is at odds with Melitz (2003). However, entry of the new firms raises demand for production workers which contributes to a positive welfare effect due to an increase in aggregate employment at constant real wages.

Under free trade, our model also provides interesting features which differ from the ones of previous work on international labor market linkages in trade models: first, it generates unemployment in all countries despite any differences in the level of minimum wages because, with 
firm heterogeneity, factor prices do not equalize (even if production is diversified and trade not subject to any impediments) and, second, it motivates a positive correlation of unemployment rates across borders in response to shocks in individual economies. With homogeneous producers, a minimum wage constraint can only be binding in one country under free trade and diversification of production (i.e., with factor price equalization). Then, a tightening of the labor market constraint in one country will raise unemployment there but prop up wages abroad as in Davis (1998). If firms differ in their productivity, minimum wage constraints may be binding in either country so that positive unemployment is ubiquitous.

With firm heterogeneity, trade only equalizes the production costs of the marginal producers but not of all firms in the international market. In this case, detrimental effects of a tightening of labor market imperfections abroad on world demand will not be offset by a relocation of production from the foreign to the home country, unlike in models with homogeneous producers. Since the contraction of the more constrained economy is moderated by a rise in average productivity of the surviving firms, while the expansion of the less constrained economy is dampened by the entry of firms with lower productivity, the increase in a country's minimum wage exhibits a negative spillover effect on the other country's labor market, thereby inducing a parallel increase in both countries' unemployment rates. This result is remarkable as it qualifies the by now conventional wisdom among policy makers on both sides of the Atlantic that Europe's reliance on high minimum wages entails an export of jobs and, hence, benefits US workers. Clearly, this effect is important and the mechanism at work is also present in our model. However, it is more than offset in equilibrium by two additional effects: the reduction in world demand as well as selection of firms into the market according to their productivity. Altogether, our analysis suggests that workers in the US should be concerned rather than happy about European unemployment.

Of course, the analysis in this paper is parsimonious in many regards. For instance, considering minimum wages as the main source of unemployment, while convenient from the perspective of analytical tractability, is quite simplistic from an empirical perspective. Certainly, in reality other labor market institutions than minimum wages may govern positive unemployment rates and these institutions may differ across countries. Also, our focus on firms which do not face a decision between producing for the local market only versus exporting disregards the fact that only a sub-sample of a country's producers acts internationally. While the basic mechanisms at work would unlikely be invalidated by considering more sophisticated reasons of labor market imperfections or by allowing for an extensive margin of exporting (apart from firm entry as such), such modifications may generate additional interesting predictions for empirical work. However, these extensions are beyond the scope of this paper and, hence, left open for future research. 


\section{Appendix}

Derivation of eq. (23)

Starting point is the price index

$$
\begin{aligned}
P=M_{t}^{\frac{1-\eta}{1-\sigma}}\left[\frac{N}{M_{t}} \int_{\phi_{A}}^{\infty} p_{A}(\phi)^{1-\sigma} g(\phi) d \phi+\frac{N}{M_{t}} \int_{\phi_{E}^{m}}^{\infty} p_{A}(\phi)^{1-\sigma} g(\phi) d \phi\right. & \\
& \left.+\frac{N}{M_{t}} \int_{\phi_{E}^{*}}^{\phi_{E}^{m}} p_{E}(\phi)^{1-\sigma} g(\phi) d \phi\right]^{\frac{1}{1-\sigma}} .
\end{aligned}
$$

Noting $p_{E}(\phi) / p_{A}(\phi)=w_{E} / w_{A}$, further implies

$$
\begin{aligned}
P=M_{t}^{\frac{1-\eta}{1-\sigma}} p_{A}\left(\tilde{\phi}_{A}\right)\left[\frac{N}{M_{t}} \int_{\phi_{A}}^{\infty}\left(\frac{\phi}{\tilde{\phi}_{A}}\right)^{\sigma-1} g(\phi) d \phi\right. & +\frac{N}{M_{t}} \int_{\phi_{E}^{m}}^{\infty}\left(\frac{\phi}{\tilde{\phi}_{A}}\right)^{\sigma-1} g(\phi) d \phi \\
& \left.+\frac{N}{M_{t}}\left(\frac{w_{E}}{w_{A}}\right)^{1-\sigma} \int_{\phi_{E}^{*}}^{\phi_{E}^{m}}\left(\frac{\phi}{\tilde{\phi}_{A}}\right)^{\sigma-1} g(\phi) d \phi\right]^{\frac{1}{1-\sigma}} .
\end{aligned}
$$

Substituting $p_{A}\left(\tilde{\phi}_{A}\right)=\left(\tilde{\phi}_{A t} / \tilde{\phi}_{A}\right) p_{A}\left(\tilde{\phi}_{A t}\right), M_{t}^{(1-\eta) /(1-\sigma)} p_{A}\left(\tilde{\phi}_{A t}\right)$ and using

$$
\tilde{\phi}_{i} \equiv\left[\frac{N}{M_{i}} \int_{\phi_{i}}^{\infty} \phi^{\sigma-1} g(\phi) d \phi\right]^{\frac{1}{\sigma-1}}
$$

from the analysis of the closed economy, eq. (A2) can be rewritten in the following way

$$
\tilde{\phi}_{A t}=\left[\frac{M_{A}}{M_{t}}+\frac{N}{M_{t}} \int_{\phi_{E}^{m}}^{\infty}\left(\frac{\phi}{\tilde{\phi}_{A}}\right)^{\sigma-1} g(\phi) d \phi+\frac{N}{M_{t}}\left(\frac{w_{E}}{w_{A}}\right)^{1-\sigma} \int_{\phi_{E}^{*}}^{\phi_{E}^{m}}\left(\frac{\phi}{\tilde{\phi}_{A}}\right)^{\sigma-1} g(\phi) d \phi\right]^{\frac{1}{\sigma-1}} \tilde{\phi}_{A} .
$$

We can now consider

$$
\begin{aligned}
& \frac{N}{M_{t}} \int_{\phi_{E}^{m}}^{\infty}\left(\frac{\phi}{\tilde{\phi}_{A}}\right)^{\sigma-1} g(\phi) d \phi=\frac{M_{A}}{M_{t}}\left(\frac{\phi_{F}^{m}}{\phi_{A}^{*}}\right)^{\sigma-1-k}, \\
& \frac{N}{M_{t}}\left(\frac{w_{E}}{w_{A}}\right)^{1-\sigma} \int_{\phi_{E}^{*}}^{\phi_{E}^{m}}\left(\frac{\phi}{\tilde{\phi}_{A}}\right)^{\sigma-1} g(\phi) d \phi=\frac{M_{E}}{M_{t}}\left[1-\left(\frac{\phi_{F}^{m}}{\phi_{F}^{*}}\right)^{\sigma-1-k}\right]
\end{aligned}
$$

to arrive at

$$
\begin{aligned}
\tilde{\phi}_{A t} & =\left\{\frac{M_{A}}{M_{t}}+\frac{M_{E}}{M_{t}}\left[1-\left(\frac{\phi_{F}^{m}}{\phi_{F}^{*}}\right)^{\sigma-1-k}\right]+\frac{M_{A}}{M_{t}}\left(\frac{\phi_{F}^{m}}{\phi_{A}^{*}}\right)^{\sigma-1-k}\right\}^{\frac{1}{\sigma-1}} \tilde{\phi}_{A} \\
& =\left[1-\frac{M_{E}}{M_{t}}\left(\frac{\phi_{F}^{m}}{\phi_{F}^{*}}\right)^{\sigma-1-k}+\frac{M_{A}}{M_{t}}\left(\frac{\phi_{F}^{m}}{\phi_{A}^{*}}\right)^{\sigma-1-k}\right]^{\frac{1}{\sigma-1}} \tilde{\phi}_{A} .
\end{aligned}
$$


If we make use (16), (22), $\chi=\left(\phi_{E}^{m} / \phi_{e}^{*}\right)^{-k}$ and $M_{t}=M_{F}\left[\left(w_{E} / w_{A}\right)^{k}+1\right]$, we can reformulate the latter expression to

$$
\begin{aligned}
\tilde{\phi}_{A t} & =\left[1+\frac{\left[\left(w_{E} / w_{A}\right)^{\sigma-1}-1\right]^{\frac{k}{\sigma-1}}}{\left(w_{E} / w_{A}\right)^{k}+1}\right]^{\frac{1}{\sigma-1}} \tilde{\phi}_{A} \\
& =\left[1+\frac{\chi}{\left(w_{E} / w_{A}\right)^{k}+1}\right]^{\frac{1}{\sigma-1}} \tilde{\phi}_{A},
\end{aligned}
$$

which confirms the relationship between $\tilde{\phi}_{i t}$ and $\tilde{\phi}_{i}$ in (23) for the US. Finally, to check whether eq. (23) is a correct description of the relationship between the two averages in Europe, we can account for (16) and substitute $p_{E}\left(\tilde{\phi}_{E}\right)=p_{A}\left(\tilde{\phi}_{A}\right)$ in eq. (A2). Then, following the formal steps from above, we obtain

$$
\tilde{\phi}_{E t}=\left[1+\frac{\chi}{\left(w_{E} / w_{A}\right)^{k}+1}\right]^{\frac{1}{\sigma-1}} \tilde{\phi}_{E},
$$

which confirms that (23) is also valid for Europe.

\section{References}

Baldwin, R. (2005): "Heterogeneous Firms and Trade: Testable and Untestable Properties of the Melitz Model," NBER Working Paper No. 11471.

Bernard, A. B., and J. B. Jensen (1995): "Exporters, Jobs, and Wages in U.S. Manufacturing: 1976-1987," Brookings Papers on Economic Activity - Microeconomics, 1995, 67-112.

(1999): "Exceptional Exporter Performance: Cause, Effect, or Both?," Journal of International Economics, 47(1), 1-25.

Brecher, R. A. (1974): "Minimum Wage Rates and the Pure Theory of International Trade," Quarterly Journal of Economics, 88(1), 98-116.

Davidson, C., S. J. Matusz, and A. Shevchenko (2008): "Globalization and Firm Level Adjustment with Imperfect Labor Markets," Journal of International Economics, 75(2), 295309.

DAvis, D. R. (1998): "Does European Unemployment Prop Up American Wages? National Labor Markets and Global Trade," American Economic Review, 88(3), 478-494.

Davis, D. R., And J. Harrigan (2007): "Good Jobs, Bad Jobs, and Trade Liberalization," NBER Working Paper No. 13139. 
Del Gatto, M., G. Mion, and G. I. P. Ottaviano (2006): "Trade Integration, Firm Selection and the Costs of Non-Europe," CEPR DP No. 5730.

Do, Q.-T., And A. A. Levchenko (2009): "Trade, Inequality, and the Political Economy of Institutions," Journal of Economic Theory, forthcoming.

Eckel, C., AND H. EgGer (2009): "Wage bargaining and multinational firms," Journal of International Economics, 77(2), 206-214.

EgGer, H., And U. Kreickemeier (2009): "Firm Heterogeneity and the Labor Market Effects of Trade Liberalization," International Economic Review, 50(1), 187-216.

EthieR, W. J. (1982): "National and International Returns to Scale in the Modern Theory of International Trade," American Economic Review, 72(3), 389-405.

Helpman, E. (1984): "A Simple Theory of International Trade with Multinational Corporations," Journal of Political Economy, 92(3), 451-471.

Helpman, E., O. Itskhoki, and S. Redding (2008): "Inequality and Unemployment in a Global Economy," NBER Working Paper No. 14478.

Kreickemeier, U., And D. Nelson (2006): "Fair Wages, Unemployment and Technological Change in a Global Economy," Journal of International Economics, 70(2), 451-469.

Krugman, P. R. (1994): "Past and Prospective Causes of High Unemployment," Federal Reserve Bank of Kansas City Economic Review, 79(4), 23-43.

Lommerud, K. E., F. Meland, and L. Sørgard (2003): "Unionised oligopoly, trade liberalisation and location choice," Economic Journal, 113(490), 782-800.

Markusen, J. R. (1989): "Trade in Producer Services and in Other Sepecialized Intermediate Inputs," American Economic Review, 79(1), 85-95.

(2002): Multinational Firms and the Theory of International Trade. The MIT Press.

MeckL, J. (2006): "Does European Unemployment Prop Up American Wages? National Labor Markets and Global Trade: Comment," American Economic Review, 96(5), 1924-1930.

Melitz, M. J. (2003): "The Impact of Trade on Intra-industry Reallocations and Aggregate Industry Productivity," Econometrica, 71(6), 1695-1725.

Nickell, S. (1997): "Unemployment and Labor Market Rigidities: Europe versus North America," Journal of Economic Perspectives, 11(3), 55-74. 
Patacchini, E., And Y. Zenou (2007): "Spatial Dependence in Local Unemployment Rates," Journal of Economic Geography, 7(2), 169-181.

Scheve, K. F., And M. J. Slaughter (2001): Globalization and the perceptions of American workers. Institute for International Economics.

Südekum, J. (2005): "Increasing Returns and Spatial Unemployment Disparities," Papers in Regional Science, 84(2), 159-181.

Skaksen, M. Y., And J. R. SøRensen (2001): "Should trade unions appreciate foreign direct investment," Journal of International Economics, 55(2), 369-390. 